\title{
Characterizing Spatiotemporal Variations of Hourly Rainfall by Gauge and Radar in the Mountainous Three Gorges Region
}

\author{
ZHE LI AND DAWEN YANG \\ State Key Laboratory of Hydroscience and Engineering, Department of Hydraulic Engineering, Tsinghua University, Beijing, China \\ YANG HONG \\ Hydrometeorology and Remote Sensing Laboratory, Department of Civil Engineering and Environmental Science, University of \\ Oklahoma, and Advanced Radar Research Center, National Weather Center, Norman, Oklahoma \\ JIAN ZHANG \\ NOAA/National Severe Storms Laboratory, Norman, Oklahoma \\ YOUCUN QI \\ Cooperative Institute for Mesoscale Meteorological Studies, University of Oklahoma, and NOAA/OAR/National Severe Storms \\ Laboratory, Norman, Oklahoma, and College of Atmospheric Science, Nanjing University of \\ Information Science and Technology, Nanjing, China
}

(Manuscript received 30 August 2013, in final form 20 November 2013)

\begin{abstract}
Understanding spatiotemporal rainfall patterns in mountainous areas is of great importance for prevention of natural disasters such as flash floods and landslides. There is little knowledge about rainfall variability over historically underobserved complex terrains, however, and especially about the variations of hourly rainfall. In this study, the spatiotemporal variations of hourly rainfall in the Three Gorges region (TGR) of China are investigated with gauge and newly available radar data. The spatial pattern of hourly rainfall has been examined by a number of statistics, and they all show that the rainfall variations are time-scale and location dependent. In general, the northern TGR receives more-intense and longer-duration rainfall than do other parts of the TGR, and short-duration storms could occur in most of the TGR. For temporal variations, the summer diurnal cycle shifts from a morning peak in the west to a late-afternoon peak in the east while a mixed pattern of two peaks exists in the middle. In statistical terms, empirical model-based estimation indicates that the correlation scale of hourly rainfall is about $40 \mathrm{~km}$. Further investigation shows that the correlation distance varies with season, from $30 \mathrm{~km}$ in the warm season to $60 \mathrm{~km}$ in the cold season. In addition, summer rainstorms extracted from radar rainfall data are characterized by short duration (6-8 h) and highly localized patterns (5-17 and $13-36 \mathrm{~km}$ in the minor and major directions, respectively). Overall, this research provides quantitative information about the rainfall regime in the TGR and shows that the combination of gauge and radar data is useful for characterizing the spatiotemporal pattern of storm rainfall over complex terrain.
\end{abstract}

\section{Introduction}

Characterizing the rainfall variability at a range of spatial and temporal scales is of critical importance for many applications in hydrology and meteorology (Smith and Krajewski 1991; Heistermann and Kneis 2011; Li

Corresponding author address: Dawen Yang, Rm. 312, New Hydraulic Engineering Bldg., Dept. of Hydraulic Engineering, Tsinghua University, Beijing 100084, China.

E-mail: yangdw@tsinghua.edu.cn et al. 2012), especially for those natural hazards, such as floods and landslides, that are linked with rainfall extremes (Hong et al. 2006; Wu et al. 2012). In the past, considerable efforts, spanning from annual to daily in time and from global to kilometric in space, have been made to address this issue. In contrast, in earlier times little attention has been focused on the small-scale variations of rainfall, perhaps because of data limitations. Recent studies, however, have claimed that a small-scale rainfall pattern has value in enhancing the modeling of land 
surface processes (Foufoula-Georgiou and Vuruputur 2001), including the partitioning of rainfall into different components of the hydrologic cycle (Winchell et al. 1998; Balme et al. 2006; Morin et al. 2006).

Despite its crucial role in hydrometeorology, adequate characterization of the space-time variability of rainfall remains a challenge because of its great heterogeneity across a variety of spatiotemporal scales (Harris et al. 2001; Nicótina et al. 2008; Sorooshian et al. 2011). In particular, quantitative rainfall estimation over mountainous areas often has significant uncertainty, perhaps induced by insufficient sampling resulting from the scarcity of gauge observations (Clark and Slater 2006; Mishra and Coulibaly 2009). Moreover, the complex terrain often induces extremely localized storms as a result of orographic effects, which leads to additional difficulty for rainfall estimation in mountainous regions (Daly et al. 1994; Buytaert et al. 2006; Haile et al. 2009). As an alternative data source, weather radar has been recognized for its great potential to provide highresolution rainfall data (Berne and Krajewski 2013), which may be helpful in storm monitoring and flood prediction over these mountainous regions (Germann et al. 2006; Delrieu et al. 2009; Gourley et al. 2009). It is also stated that careful design of radar sampling strategies and rainfall retrieval algorithms is required to fully utilize radar information, however (Young et al. 1999; Zhang et al. 2012). Given the hostile observing environment, characterization of rainfall variability in mountainous areas should be resolved by assimilating information from multiple data sources (Zhang et al. 2012).

In this study, we focus on the Three Gorges region (TGR) of the Yangtze River in China to analyze the spatiotemporal variations of rainfall. This mountainous area is located in the transition zone between two monsoon systems: the Asian southeastern summer monsoon and the Indian southwestern monsoon (Zhao et al. 2010; Zhou et al. 2011), and this climatic feature, combined with local irregular terrain, has shaped the TGR's complicated rainfall regime. As a previous study indicated, floods generated in this region have fast and significant effects on the Three Gorges Reservoir's operation ( $\mathrm{Li}$ et al. 2013); therefore, the ability to interpret and quantify the regional rainfall variability-especially the small-scale variations closely related to hydrometeorological extremes-has great implications for flood prediction in this focal region. To our knowledge, previous studies have examined the climatic effects of the Three Gorges Reservoir (Miller et al. 2005; Wu et al. 2006); the decadal variation of the annual rainfall regime (Xiao et al. 2010); and the seasonal, monthly, and daily rainfall regimes (Zhao et al. 2010; Zhao and Shepherd
2012) in the TGR. The critical issue of small-scale variations of TGR rainfall has never been addressed before, however, mainly because of the lack of high-resolution rainfall data. Both a dense gauge network and weather radar have recently become available, allowing us to investigate the undiscovered aspects of the regional rainfall regime by using multiple rainfall data sources.

Motivated by this idea to characterize the complicated hourly rainfall regime in the TGR, we focus on two fundamental questions: 1) What is the general pattern of TGR hourly rainfall variations in both space and time? and 2) Is the current gauge network sufficiently dense for monitoring summer rainstorms in the TGR? In answering the first question, we collected hourly gauge data from two recent years to statistically analyze the spatial variations and the diurnal cycle of regional rainfall. Further, to address the second question, we believe that the representative scales of both gauge observations and summer rainstorms should be estimated and compared by synthesizing gauge and newly available radar data.

The remaining parts of this paper are organized as follows: the study area and datasets are described in section 2, including a brief introduction of the radar data and their retrieval algorithms. Section 3 presents the general pattern of space-time variations for hourly rainfall. In section 4 , the spatial correlation of gauge records and the geometric features of summer rainstorms are analyzed by synthesizing gauge and radar data. Section 5 concludes this paper with a discussion of the results and a summary of the major findings.

\section{Study area and data}

\section{a. The study area}

The study area, called the Three Gorges region, is shown in Fig. 1. The Three Gorges Dam is located at the east end of the TGR, and it forms a long and narrow reservoir that almost spans the whole TGR. Note that the geographical extent of the TGR in this paper is slightly different from that of previous studies by others: the TGR here is defined as the drainage area from the hydrological perspective. The total area of the TGR covers nearly $60000 \mathrm{~km}^{2}$, and the elevation ranges from 15 to $3090 \mathrm{~m}$. The main stream of the Yangtze River (the dark gray line in Fig. 1) stretches for $650 \mathrm{~km}$ from Chongqing to Yichang and divides the whole narrow region into north and south sides. Because of the complex terrain in the TGR, there are lots of small tributaries, which directly drain TGR-generated floods into the main Yangtze. As claimed in a previous study (Zhang et al. 1999), local floods generated in the TGR often 


\section{Yangtze River Basin and Three Gorges Region (TGR) in China}

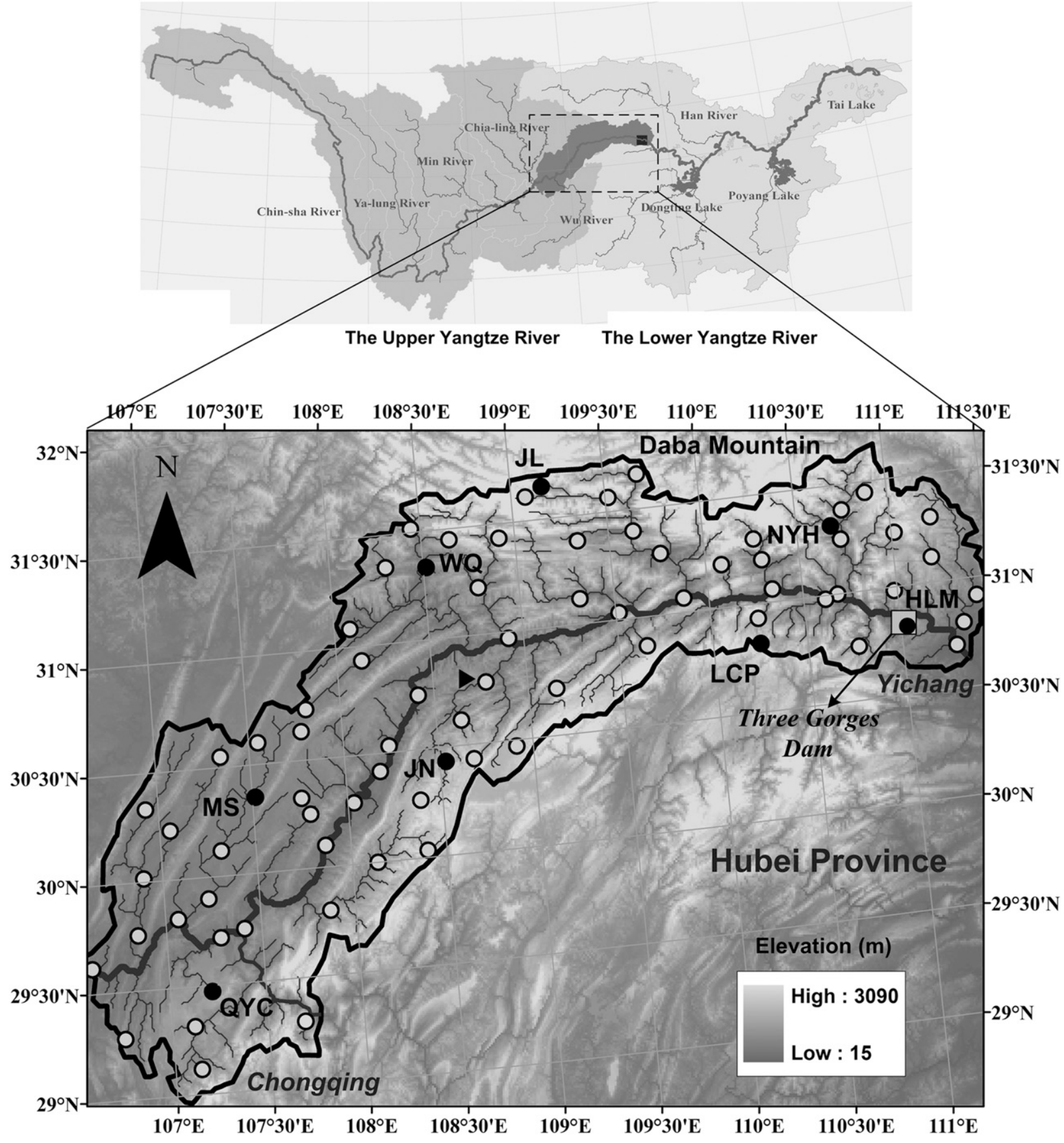

FIG. 1. (top) The TGR and its location in the Yangtze River Basin. (bottom) The details of the TGR, including rain gauges, radar location, and terrain. The symbols and lines are described in the text.

exceed $10000 \mathrm{~m}^{3} \mathrm{~s}^{-1}$ during extreme storm events and immediately affect the peak flow entering the reservoir. The TGR contains the Daba Mountains and southwestern Hubei rainstorm areas in China, and annual rainfall varies from 900 to $1400 \mathrm{~mm}$ with locally intensified rainfall over the regions of complex terrain
(Zhao and Shepherd 2012). In general, floods of the Yangtze River are triggered by high-intensity and longlasting rainfall, which is governed by the typical monsoon climate. Thus, the flood season in the TGR starts in May and continues until September, which corresponds to the mei-yu (plum rain) season. 


\section{b. Rainfall data}

\section{1) Gauge data}

After the Three Gorges Reservoir started to store water in June of 2003, a gauge network for regional rainfall monitoring was installed by the China Three Gorges Corporation (CTGC) to enhance the ability to detect local rainstorms for regional flood prediction. This network consists of 78 automatic tipping-bucket gauges (circles in Fig. 1), which are distributed almost evenly over the whole region. It is reported that these gauges have a funnel diameter of $200 \mathrm{~mm}$ with a resolution of $0.2 \mathrm{~mm}$ and measurement range of 0 $240 \mathrm{~mm} \mathrm{~h}^{-1}$. Although the gauge network had been in preoperation mode since 2004, it did not shift to formal operation mode until autumn of 2009; thus, we only adopt two recent years (October 2009-September 2011) of gauge hourly rainfall records as the analysis data. It is claimed that all gauges have been calibrated and that the data have been collected with quality control during this operation mode (T. Xu, CTGC, 2013, personal communication). To ensure good data quality, we also carried out a cross-validation test by comparing accumulated daily rainfall from the CTGC gauges during the 2-yr study period with coincident daily records from the nearby China Meteorological Administration (CMA) gauges (four pairs of gauges are found for this dataquality test). The result indicates that the correlation values between the two datasets are greater than 0.95 with averaged root-mean-square error (RMSE) of $\sim 2.5 \mathrm{~mm} \mathrm{day}^{-1}$, suggesting that the CTGC data have been collected with reasonable accuracy.

\section{2) RADAR RAINFALL DATA}

In 2007, an S-band Doppler radar (the triangle in Fig. 1), located at the center of the TGR, was installed by the CMA. When this radar is switched to precipitation mode, it collects data every $6 \mathrm{~min}$ up to a maximum range of $460 \mathrm{~km}$, operating at nine elevation angles ranging from $0.5^{\circ}$ to $19.5^{\circ}$. The range resolution is $1 \mathrm{~km}$ while the azimuth resolution is $1^{\circ}$, and to get rainfall estimates that are suitable for hydrological analysis we resample the radar bin retrievals into Cartesian grids with a spatial resolution of $1 \mathrm{~km}$ for each hour.

We developed the initial radar rainfall $R$ retrieval algorithms to estimate TGR rainfall. In brief, procedures for TGR radar quantitative precipitation estimates (QPE) consist of beam-blockage analysis, hybrid-scan composite reflectivity $Z$, ground-clutter filter, convective/ stratiform segmentation, adaptive $Z-R$ relations, and spatiotemporal resampling. Several parts of these algorithms follow the procedures proposed in a number of previous studies on radar QPE (Kucera et al. 2004;
Zhang et al. 2011; Qi et al. 2013). Because there are no previous specific local studies on both raindrop size distribution and $Z-R$ relationship for the TGR, here we use general $Z-R$ relationships (Qi et al. 2013) in this preliminary study.

We also produced hourly radar rainfall products $(1-\mathrm{km}$ grids) for the time period of June-September 2010. We found that the averaged bias (defined as the ratio between radar estimates and gauge measurements) is approximately 1.2 within $150-\mathrm{km}$ range while the probability of detection is approximately $70 \%$. The hourly radar rainfall fields are analyzed storm by storm in the current study, and typical geometrical features of rainstorms are characterized.

\section{General pattern of space-time variations}

From the gauge-network observations, several statistical indices are calculated to study the spatial variations of hourly rainfall. For the temporal variations, we focus on the diurnal cycle and its spatial dependence in the TGR.

\section{a. Spatial variations of hourly rainfall}

The statistical indices include the mean, median, standard deviation, interquartile range, coefficient of variance $(\mathrm{CV}$ : the standard deviation divided by the mean), rainfall occurrence percentage (the rainy hours divided by the total hours of the 2-yr gauge records), conditional mean rainfall (the total rainfall amount divided by the rainy hours), and maximum rainfall accumulated with different time scales (e.g., 1, 6, 12, and $24 \mathrm{~h}$ ). The probability of exceedance, as a more informative way to describe rainfall data samples (Ciach and Krajewski 2006), is also considered in the study. The frequency distributions of several representative gauges in the TGR with different time scales are compared.

The summary statistics of conditional hourly rainfall from eight representative gauges (see Fig. 1) are shown in Table 1. When hours with no rain are taken into consideration, the median and the interquartile range (i.e., the difference between the first quartile and the third quartile) are 0 (not shown in Table 1), reflecting the intermittent nature of rainfall. When these dry spells (i.e., hours without rain) are excluded from the analysis, the median and the interquartile range become $0.4-0.6$ and $0.8-2.2 \mathrm{~mm}$, respectively. At the same time, high values of skewness and kurtosis suggest that hourly rainfall in the TGR exhibits a right-tailed distribution with relatively high temporal variability.

It is also noteworthy that these statistics have implications to link the rainfall spatial pattern with terrain. First, the JL and LCP gauges, which are located in the high-altitude region, show greater maximum rainfall 
TABLE 1. Statistics of conditional hourly rainfall (eight representative gauges) in the TGR. The locations associated with the site identifiers are given in Fig. 1.

\begin{tabular}{|c|c|c|c|c|c|c|c|c|}
\hline & QYC & MS & $\mathrm{JN}$ & WQ & $\mathrm{JL}$ & LCP & NYH & HLM \\
\hline Elev (m) & 750 & 420 & 850 & 318 & 1045 & 1700 & 259 & 187 \\
\hline No. of hours & 1705 & 1538 & 1352 & 1446 & 1874 & 2064 & 1296 & 1291 \\
\hline Mean (mm) & 0.92 & 1.12 & 1.37 & 1.87 & 2.09 & 1.60 & 1.96 & 1.37 \\
\hline Median (mm) & 0.40 & 0.40 & 0.40 & 0.60 & 0.60 & 0.60 & 0.60 & 0.60 \\
\hline Std dev (mm) & 1.89 & 2.16 & 2.61 & 3.65 & 4.06 & 3.05 & 3.42 & 2.99 \\
\hline Q75-Q25 (mm) & 0.8 & 1.0 & 1.4 & 1.8 & 2.0 & 1.6 & 2.2 & 1.4 \\
\hline Skewness & 7.6 & 5.5 & 5.5 & 4.9 & 5.1 & 6.4 & 4.9 & 7.7 \\
\hline Kurtosis & 92.1 & 46.3 & 44.0 & 34.7 & 41.5 & 71.8 & 38.5 & 81.6 \\
\hline $\operatorname{Max}(\mathrm{mm})$ & 34.2 & 29.6 & 30.6 & 38.4 & 53.0 & 54.0 & 40.2 & 42.8 \\
\hline
\end{tabular}

(53.0 and $54.0 \mathrm{~mm}$, respectively) relative to surrounding gauges. This result, together with rainy hours, suggests that mountainous rainfall may be intensified in the form of more events and greater peaks. Second, it is obvious that all of the gauges located on the northern side of the Yangtze River (WQ, JL, and NYH; see Fig. 1) show larger conditional mean rainfall values, which indicates higher-intensity rainfall in the northern TGR than in the southern part. This result is consistent with previous investigations of rainfall in the TGR (Changjiang Water Resources Commission 1997), which also show that the northern part of the TGR, as the windward slope of the Daba Mountains, gets more high-intensity rainfall because of orographic enhancement.

Figure 2 shows the spatial distribution of several summary statistics for all gauges in the TGR. As shown in Fig. 2a, rainfall occurrence ranges from $5.6 \%$ to $12.5 \%$, and most gauges with a large proportion of rainy hours are located in the east of the TGR, as well as in the northern and southern mountainous regions. Annual accumulated rainfall is presented in Fig. $2 \mathrm{~b}$. We find that large rainfall amounts (exceeding $1000 \mathrm{~mm}$ ) are observed in the north and south mountainous areas. In contrast, large conditional mean values indicating high-intensity rainfall mainly occur in the northern TGR (not shown in Fig. 2). Combining the results in Figs. 2a and 2b suggests that, in the western TGR near Chongqing, light rainfall is frequent but that the total amount is limited. The conditioned $\mathrm{CV}$ value varies from 1.6 to 2.8 , indicating that the standard deviation always exceeds mean rainfall, which shows the high temporal variability of hourly rainfall amount in the TGR. The spatial distribution of $\mathrm{CV}$ (not shown here) suggests that the mountainous areas always have lower $\mathrm{CV}$ values than do other regions in the TGR, reflecting a temporally uniform rainfall distribution in the high-altitude mountain region.

Local flood generation is dominated by the total amount of accumulated rainfall over several hours. Thus, we also investigate the spatial pattern of maximum accumulated rainfall at different time scales $(1,6$, 12 , and $24 \mathrm{~h}$; all mean consecutive hours), and the maps for 1 and $24 \mathrm{~h}$ are shown in Fig. 3 as an illustration. From 1 to $12 \mathrm{~h}$, the maximum rainfall shows large values in many places of the TGR, suggesting that local short-duration
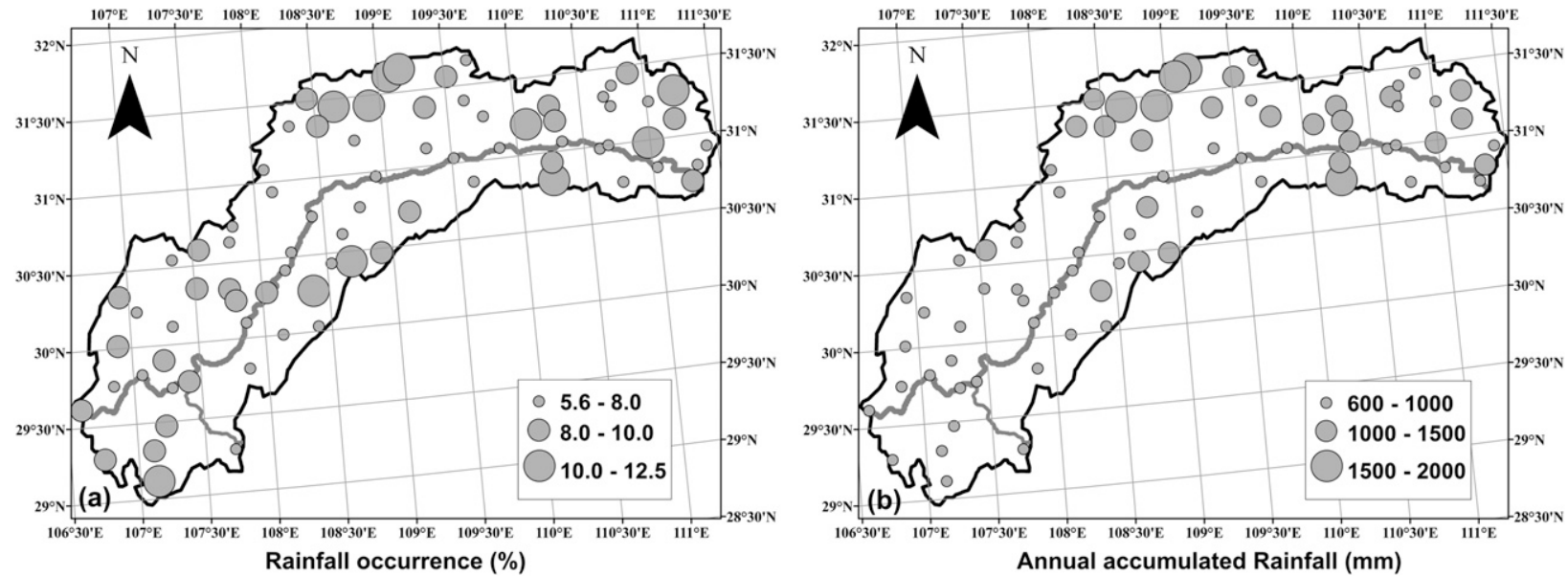

FIG. 2. Summary statistics of hourly rainfall during 2009-11, including (left) rainfall occurrence (\%) and (right) annual accumulated rainfall $(\mathrm{mm})$. 

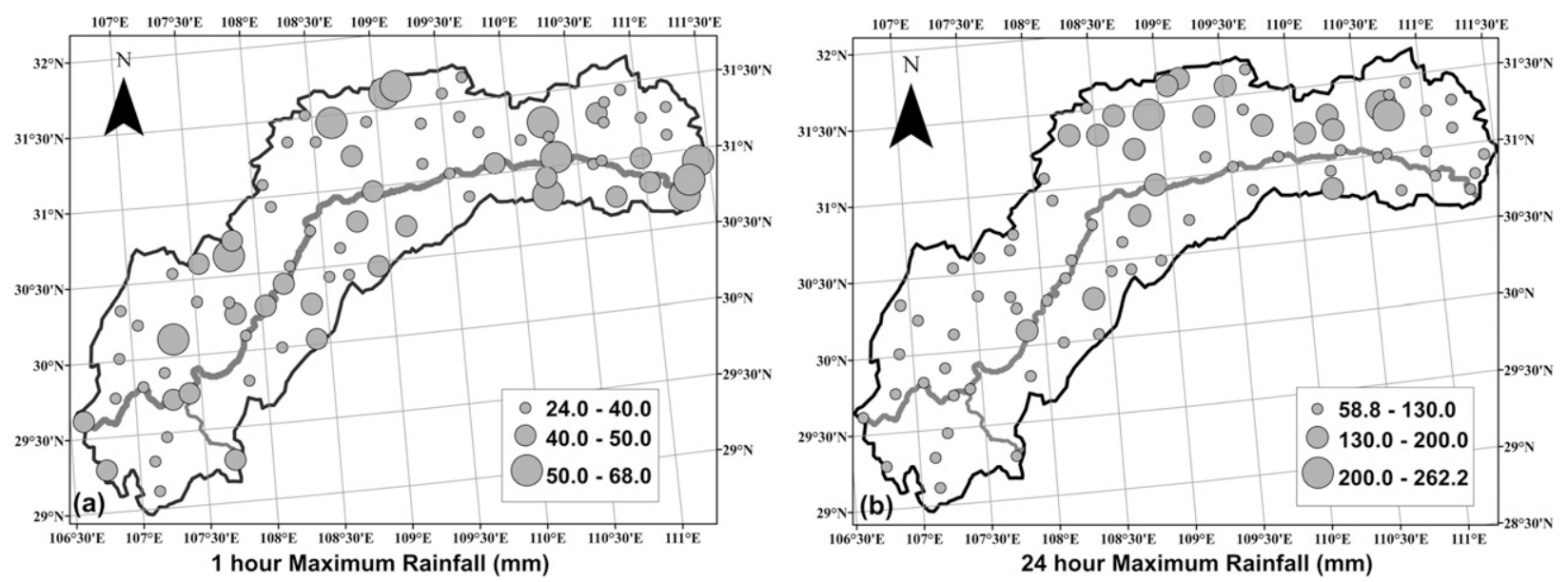

FIG. 3. Spatial maps of (left) 1- and (right) 24-h maximum rainfall in the TGR during 2009-11.

storms could occur in most areas of the TGR. In contrast, when rainfall duration becomes $24 \mathrm{~h}$ (i.e., 1 day), most of the large accumulated amounts are identified in the northern TGR near the Daba Mountains. Because long-duration, heavy rainfall tends to trigger local floods, this result indicates that the northern mountainous region of the TGR is the major source area for regional floods.

The exceedance probabilities of hourly rainfall are shown in Fig. 4. It is clear that the probability distributions are consistent across different time scales, which shows that those high-altitude gauges in mountainous regions (JL and LCP; Fig. 1) usually have higher exceedance probabilities. Figure 4 also confirms the typical spatial pattern of hourly rainfall in the TGR: the eastern part receives more heavy rain than does the west, with the largest chance of rain in the complex terrain (JL and LCP), especially in the Daba Mountains. Because Fig. 4 is plotted in log-linear scale, the almost straight lines for most gauges indicate that hourly (subdaily) rainfall in the TGR follows the exponential distribution. As we know, rainfall could be generally characterized as an intermittent stochastic process at fine time scales (hourly and daily), with a mixed-type marginal distribution, partly discrete and partly continuous (Rodríguez-Iturbe et al. 1987; Papalexiou and Koutsoyiannis 2012), but extensive studies find that there is no universal stochastic model for rainfall, and many distributions have been proposed for specific locations. Therefore, the exponential distribution characterized here has great implications for statistical modeling of rainfall spacetime processes in the TGR.

\section{b. Diurnal cycle}

To characterize the diurnal cycle of rainfall in the TGR, we focus on three elements: precipitation amount
(PA), precipitation intensity (PI), and precipitation frequency (PF). Because the measurement resolution of the gauges in the TGR is $0.2 \mathrm{~mm} \mathrm{~h}^{-1}$, this value is adopted to discriminate the rainy events from dry periods.

For each hour in a day, PA is defined as the accumulated precipitation amount for this hour averaged over the 730 days of the study period. With consideration of only rainy hours, PI is defined as the accumulated precipitation amount divided by the rainy days and $\mathrm{PF}$ is calculated as rainy days divided by 730 days for the hour being considered. In this study, the $24 \mathrm{~h}$ in a day are referred to by using Beijing time (i.e., UTC $+8 \mathrm{~h}$ ), which is consistent with gauge records.

Following the method of Zhuo et al. (2014), we first investigate the hourly peaks of PA, PF, and PI (indicated by PPA, PPF, and PPI, respectively) in a day. Figure 5 shows the spatial map and peak time of PPA, PPF, and PPI, with the peak time indicated by an arrow pointer on a circular clock dial, and the spatial distribution is interpolated by gauge statistics with the method of inverse distance weighting.

Figure 5a shows the spatial distribution of PPA and its occurrence time. It is evident that large PPA values $\left(\sim 0.34 \mathrm{~mm} \mathrm{~h}^{-1}\right)$ mainly appear in both the northern and southern mountainous regions and some others occur in the east. It is also noted that the pattern of occurrence time for PPA is complicated: PPA occurs in the morning $(\sim 0800-0900)$ in the northern mountainous area, and in the western region it tends to occur in the early morning ( $\sim 0600-0700$ ), but it changes to the afternoon or night in the eastern and southern TGR.

Similar to the PPA, the PPI $\left(\sim 3.67 \mathrm{~mm} \mathrm{~h}^{-1}\right)$ shows large values in the middle and east of the TGR, and it approximates $1.33 \mathrm{~mm} \mathrm{~h}^{-1}$ in the west (Fig. 5b). The spatial pattern of PPI occurrence time seems to be in 

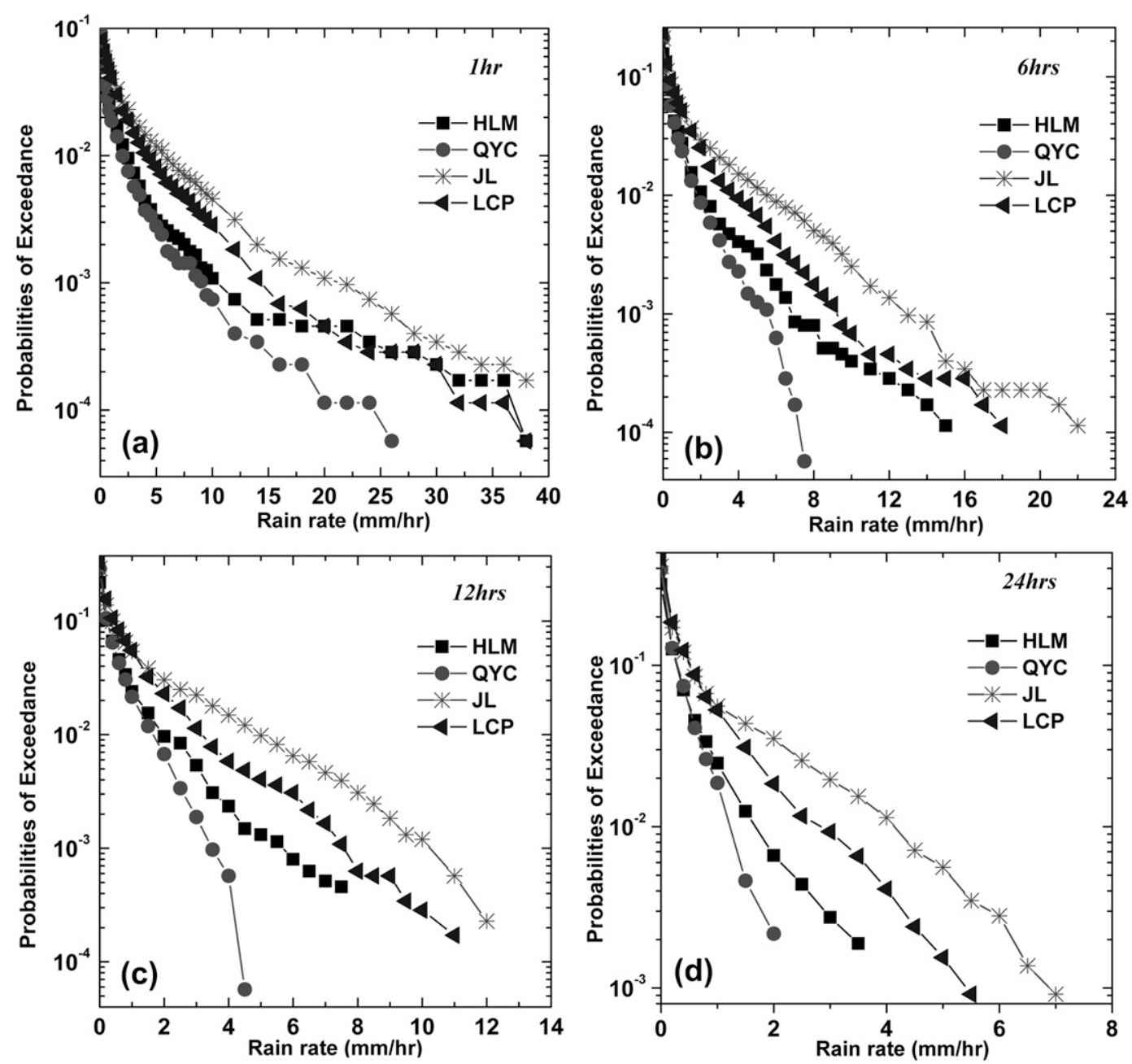

FIG. 4. Probabilities of exceedance for averaged rain rate within (a) 1, (b) 3, (c) 6, and (d) $24 \mathrm{~h}$, calculated on the basis of representative gauge observations in the TGR during 2009-11 (locations of the four gauges are indicated in Fig. 1).

disorder; thus, it is hard to decide when the peak of PI will come at any specific region in the TGR.

PPF shows a different pattern than those of PPA and PPI. In addition to being seen for the northern TGR in the Daba Mountains, high PPF values $(\sim 17.6 \%)$ also occur in the west of the TGR (Fig. 5c). This result suggests that the western part of the TGR exhibits a large number of light rainfall events, which agrees with Fig. 2. Further, this map also reveals a clear pattern for the occurrence time of PPF. In the west and middle of the TGR the PPF tends to occur in the morning, but in the east it arrives in the afternoon.

We also separately analyze the spatial pattern of summer PPA, PPI, and PPF (i.e., warm season: MaySeptember). In general, there is no remarkable change between the results of summer and those of the entire year, indicating that the diurnal pattern in the TGR is dominated by summer rainfall. The only thing that needs to be addressed is the low values of summer PPF (Fig. 5d) in the west near Chongqing, together with what is seen in Fig. 5c, which imply that this region experiences relatively frequent rain events only during the cold season.

Figure 6 shows the regional averaged diurnal cycle of PA, PI, and PF over the TGR for summer rainfall. In the top panel of Fig. 6, there are two peaks for PA. The major peak occurs around 0900 in the morning, followed by another minor peak arriving at 1600-1700 in the afternoon. For PI, similar to PA, the pattern also exhibits two obvious peaks. The first peak occurs in the morning, around 0900, and the second one also comes at 1700 in the afternoon. In strict terms, PF has only one peak at 0800 in the morning, but during $1200-1600$ its value also remains at a relatively high level. Because PA is 

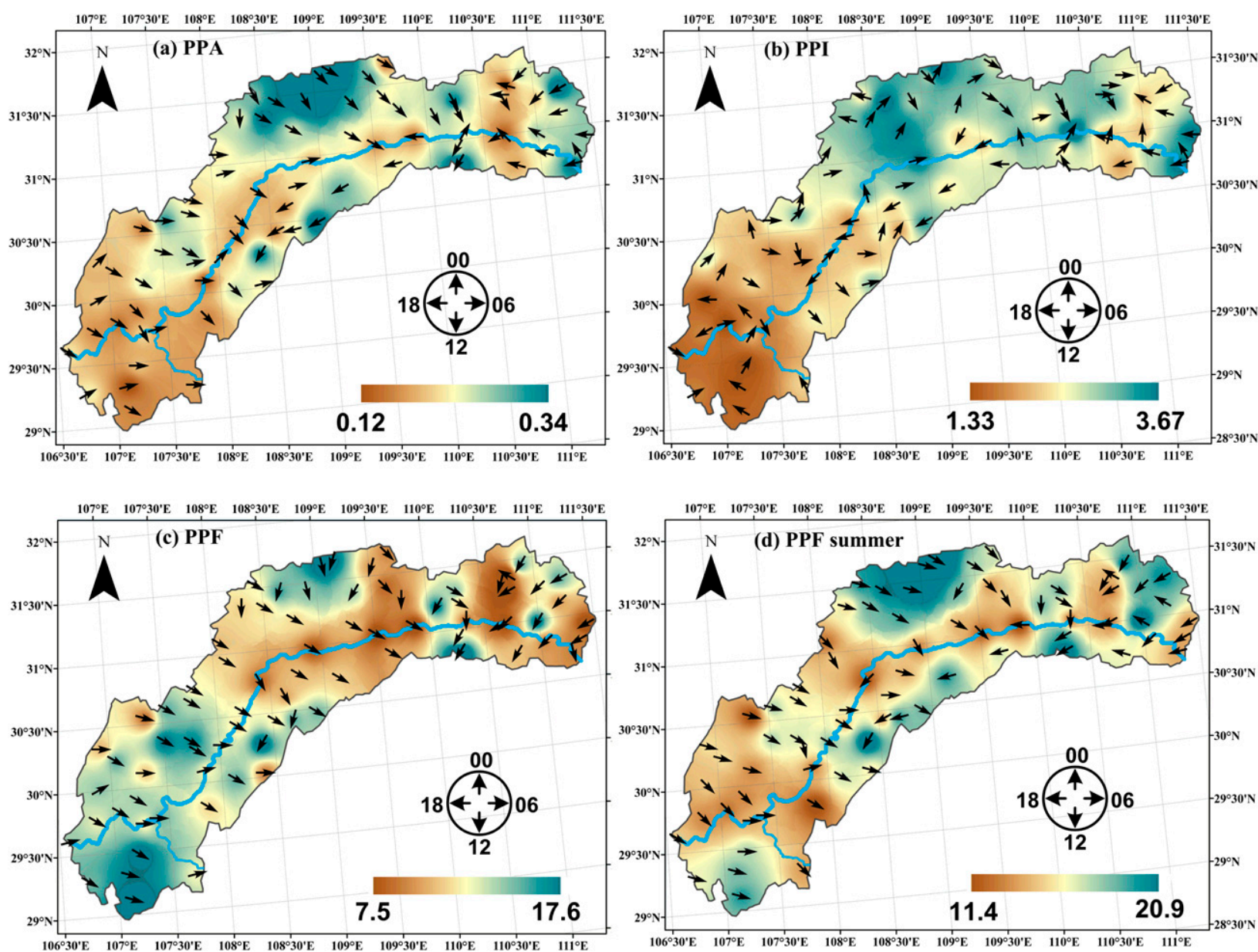

FIG. 5. Spatial distribution of (a) PPA $\left(\mathrm{mm} \mathrm{h}^{-1}\right)$, (b) PPI $\left(\mathrm{mm} \mathrm{h}^{-1}\right)$, (c) PPF (\%) for the whole year, and (d) PPF (\%) for summer (the background color indicates the magnitude of the PPA, PPI and PPF values; the arrow pointer on a circular clock dial indicates the peak time in Beijing time).

determined by both PI and PF, for the whole TGR the two-peak pattern of PA emerges. This result, focusing on TGR, is consistent with previous analysis of diurnal variations over contiguous China (Yu et al. 2007). The authors find a similar two-peak pattern of summer precipitation in central East China between the Yangtze River and the Yellow River valley, where the TGR is located. As suggested by many studies, the lateafternoon maximum can be explained by surface solar heating, which results in low-level atmospheric instability following convective rainfall, but the morning peak can be related to downward propagation of the atmospheric convective system on the leeward side of terrain (Carbone et al. 2002; Wang et al. 2004; Yu et al. 2007).

To identify spatial variations of diurnal cycle in the TGR, we divide the whole TGR into four subregions. This regionalization consists of two steps. First, we divide the whole TGR into regions I, II, and III in the west-east direction by using the $108^{\circ} 12^{\prime} \mathrm{E}$ and $110^{\circ} 00^{\prime} \mathrm{E}$ meridians. This is motivated by the fact that the TGR is in the transition zone between two monsoon systems that gradually changes from the upper to the lower Yangtze. Second, we further divide region II into a northern part (region II N) and a southern part (region II S) on the basis of the distinct rainfall regimes in these two regions as discovered above (e.g., Fig. 3d). Then, we group gauges in these four subregions to get subregional averaged diurnal cycles of summer precipitation (see Fig. 7).

After the regionalization, the diurnal cycle shows clear spatial variations within the TGR. In brief, regions I and II N seem to have a similar diurnal pattern with a morning peak around 0800 for both PA and PF; in contrast, for eastern region III the diurnal pattern shifts to the late-afternoon maximum mode for PA, PI, and PF. As the buffer zone between regions I and III, region II S shows a two-peak pattern for both PA and PF. Thus, 

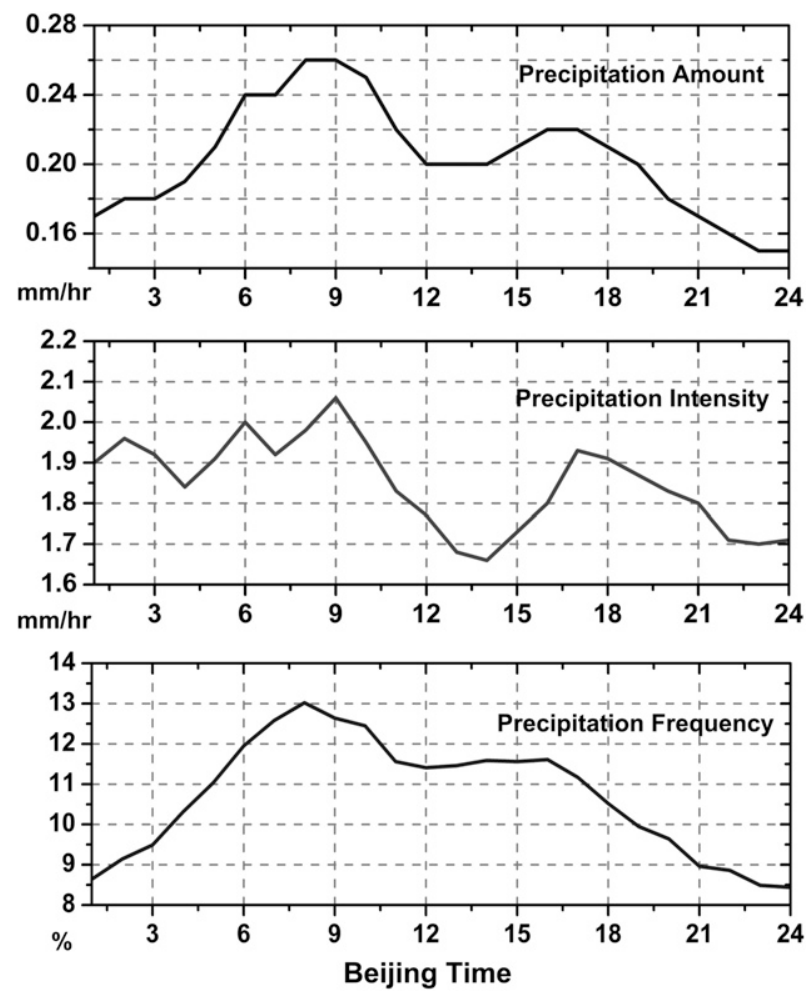

FIG. 6. Regional averaged diurnal cycle of summer PA $\left(\mathrm{mm} \mathrm{h}^{-1}\right)$, PI $\left(\mathrm{mm} \mathrm{h}^{-1}\right)$, and PF (\%) in the TGR.

we could conclude that the transition of the climate system over the TGR, in interaction with local complex terrain, has shaped the complicated precipitation regime in the TGR. The diversity of local rainfall regimes arises from the complex interactions at the terrainatmosphere interface in the TGR, which will pose a difficulty to regional hydrometeorological research, such as weather prediction, radar rainfall estimates, gauge rainfall interpolation, and flood prediction.

\section{Spatial correlation scale and summer rainstorms}

As discussed above, because of the weather system in combination with local terrain, the TGR rainfall shows complex regimes that will introduce great uncertainty to a spatial analysis of rainfall pattern that is based on only gauge data. Here we compare the correlation scale of gauge data and the scale of summer rainstorms to demonstrate the deficiency of the current gauge network for rainstorm monitoring in the TGR.

\section{a. Spatial correlation scale estimation}

It is known to all that the spatial correlation between neighboring measurements has great implications for both the descriptive mode (to infer typical scales of dominant processes) and the predictive mode (to estimate the unknowns at locations without observations) in spatial analysis (Haile et al. 2009).

Following the two-step procedure proposed by Ciach and Krajewski (2006), we infer the spatial correlation structure of hourly gauge rainfall data by fitting a modifiedexponential formula. First, we estimate the Pearson correlation for each gauge pair, taking into consideration the time series of rainfall data:

$$
r(\mathbf{X}, \mathbf{Y})=\frac{\overline{\mathbf{X Y}}-\overline{\mathbf{X}} \overline{\mathbf{Y}}}{\left[\left(\overline{\mathbf{X}^{2}}-\overline{\mathbf{X}}^{2}\right)\left(\overline{\mathbf{Y}^{2}}-\overline{\mathbf{Y}}^{2}\right)\right]^{1 / 2}},
$$

where $\mathbf{X}$ and $\mathbf{Y}$ denote the rainfall data series observed by a pair of gauges and the overbar indicates averaging over the sample time series data.

Thus, we could get the intergauge correlation value for each gauge pair (separated by a specific distance) and then fit the correlation model by the correlationdistance data samples:

$$
\rho_{g}(d)=c_{0} \exp \left[-\left(d / d_{0}\right)^{s_{0}}\right]
$$

where $c_{0}, d_{0}$, and $s_{0}$ are model parameters to be estimated and $d$ is the separation distance for gauge pairs. Parameter $c_{0}$ is usually called the nugget parameter, interpreting the correlation value for near-zero distance, and it always approximates but never equals 1 because of measurement noises; $d_{0}$ represents the typical correlation scale and is called the scale parameter, and $s_{0}$ is the shape parameter.

In general, the separation distance of gauge pairs ranges from 6 to $490 \mathrm{~km}$ in the TGR. To estimate the three parameters in Eq. (2), we determine the value of $c_{0}$ first. As suggested by previous studies (Ciach and Krajewski 2006; Haile et al. 2009), this correlation value for near-zero distances should be around 1.0; therefore, we test its value from 0.8 to 1 with an increment of 0.05 . Once $c_{0}$ is fixed, we start to search $d_{0}$ and $s_{0}$ with resolutions of 0.1 and 0.01 , respectively, to minimize the RMSE of model fitting. The two-parameter space of $\left(d_{0}\right.$, $\left.s_{0}\right)$ is defined as $0-500$ for $d_{0}$ and $0-2$ for $s_{0}$.

We estimate the spatial correlation structure by fitting the empirical model [Eq. (2)] at multiple time scales $(1,6,12$, and $24 \mathrm{~h})$, and estimated curves are shown in Fig. 8, labeled with the optimal parameters.

For hourly precipitation the optimal value of $c_{0}$ is 0.9 , but for other time scales this value is 1 . This fact indicates that, for precipitation at smaller time scales, gauge measurements may contain more noise that makes $c_{0}$ deviate from its ideal value, but this noise could be filtered out when the rain rate is averaged over large time intervals. Figure 8a shows that the correlation distance $d_{0}$ of TGR hourly precipitation is about $43 \mathrm{~km}$, 

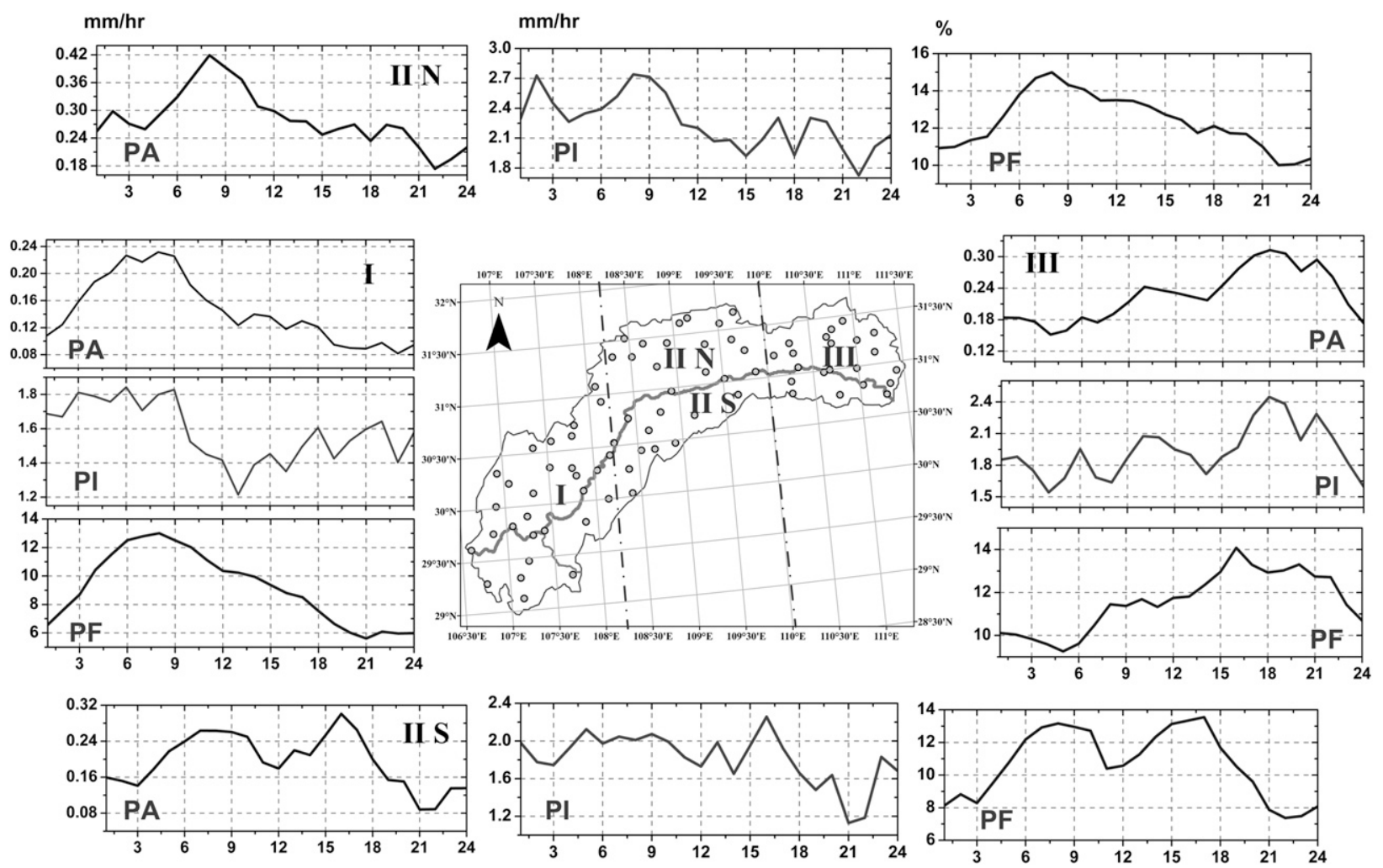

FIG. 7. Subregional averaged diurnal cycle of summer PA $\left(\mathrm{mm} \mathrm{hr}^{-1}\right), \mathrm{PI}\left(\mathrm{mm} \mathrm{hr}^{-1}\right)$, and PF (\%) in the TGR.

with a shape parameter $s_{0}$ of 0.50 . Therefore, the estimated correlation curve shows a sharp decline within tens of kilometers, and then the correlation value falls below 0.2 when another gauge is located beyond $100 \mathrm{~km}$. This result suggests that the correlation of hourly rainfall in the TGR is relatively localized. At the same time, Fig. 8 demonstrates the dependence of correlation structure on time scale. In summary, when the averaging time interval is longer, both shape parameter $s_{0}$ and correlation distance $d_{0}$ are larger. In short, 6-h-averaged rainfall shows a correlation value of 0.4 at a separation distance of $100 \mathrm{~km}$ whereas daily (i.e., $24 \mathrm{~h}$ ) rainfall shows a correlation value of greater than 0.5 at a distance of $100 \mathrm{~km}$. This time-scale-dependent behavior could be explained by the fact that long-duration rainfall is always induced by large-scale weather systems rather than by localized rainstorms.

It is well known that weather systems in the warm season may be distinguished from those in the cold season (Ebert et al. 2007). Therefore, we separately analyze the spatial correlation structure of hourly rainfall during the warm and cold seasons. Since rainfall mainly comes during May-September in the TGR, we define this period as the warm season, and label the rest as the cold season. Figure 9 shows the estimated correlation function in both seasons. It is clear that the correlation scale $d_{0}$ in the warm season $(31.3 \mathrm{~km})$ is just one-half of that in the cold season $(62.5 \mathrm{~km})$, although there is no change of $s_{0}$. This is a manifestation of the transition of precipitation systems in the two seasons: warm-season rainfall is dominated by more localized rainstorms whereas rainfall in the cold season is always controlled by the largescale stratiform-type precipitating weather.

\section{b. Radar-based analysis of summer rainstorms}

Considering the decorrelation of summer rainfall within tens of kilometers, perhaps it is still insufficient to characterize the features of local rainstorms in summer by gauge only, although the current gauge network covers the TGR with relatively high density. A stormby-storm analysis is thus performed on hourly radar rainfall data (1-km grids) from June to August in 2010 (September is excluded because of the lack of rainstorms in that month) and mainly consists of three steps.

Step 1 is threshold-based identification. The potential rainstorm regions are defined as pixels that exhibit rainfall intensity above a given threshold $R_{T}$ (Figs. 10a,b). It is obvious that more storm pixels will emerge when the threshold is set lower. Following the suggestions given by a previous study (Dixon and Wiener 1993), and 

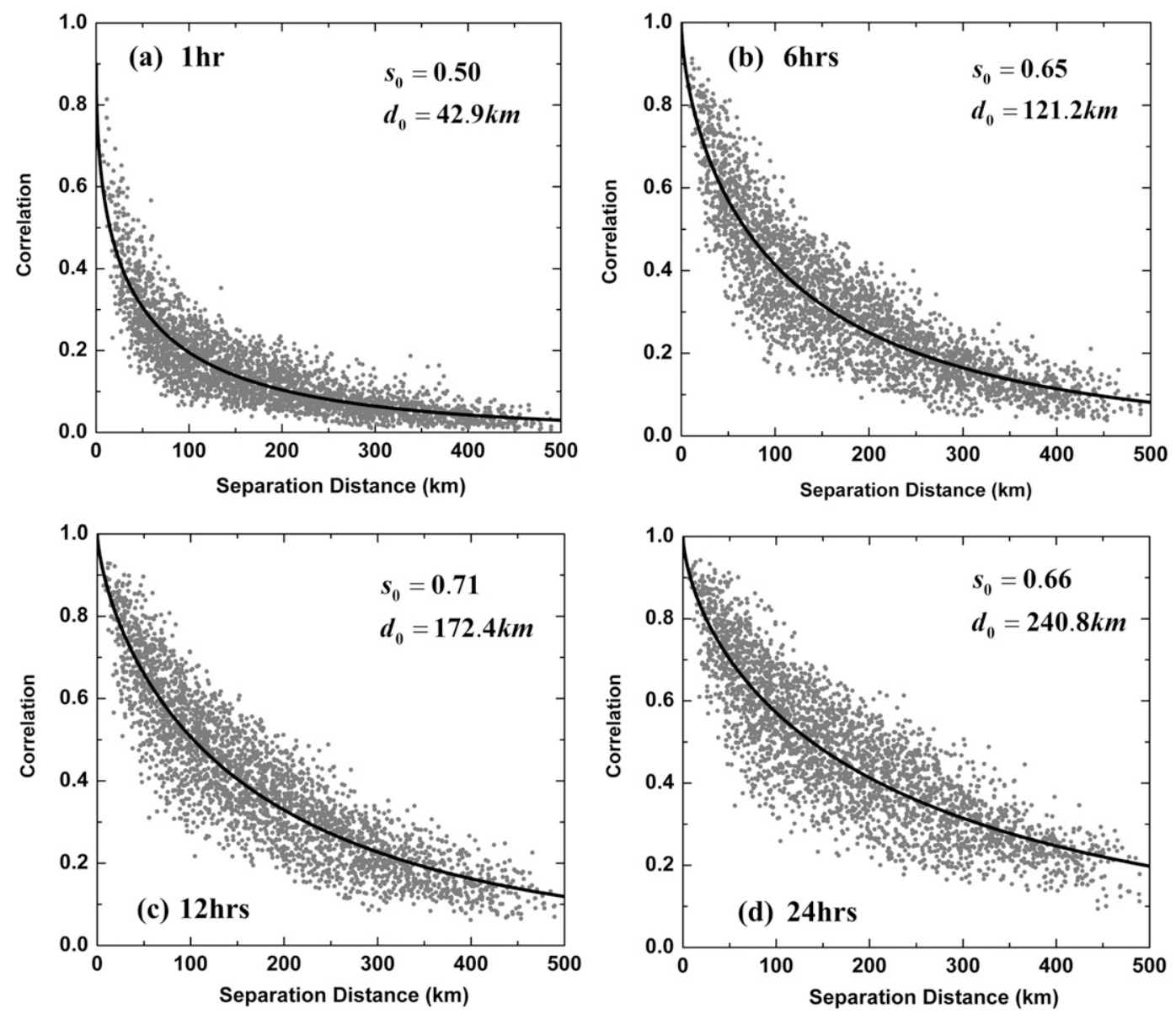

FIG. 8. Spatial correlation structure of (a) 1-, (b) 6-, (c) 12- and (d) 24-h rainfall in the TGR during 2009-11.

as also indicated by our initial tests, we set $R_{T}=$ $10 \mathrm{~mm} \mathrm{~h}^{-1}(\sim 39 \mathrm{dBZ})$. In general terms, this value is relatively high, but we use it to illustrate those cases of intensive local storms [this value is lower than the definition of rainstorms that is given by the CMA (available online at http://www.cma.gov.cn/2011qxfw/2011qqxkp/ 2011qkpdt/201205/t20120508_172024.html)].

Step 2 is rain-cell segmentation. On the basis of the contiguous region identified in step 1 , we use regiongrowing algorithms to segment major rain cells in each
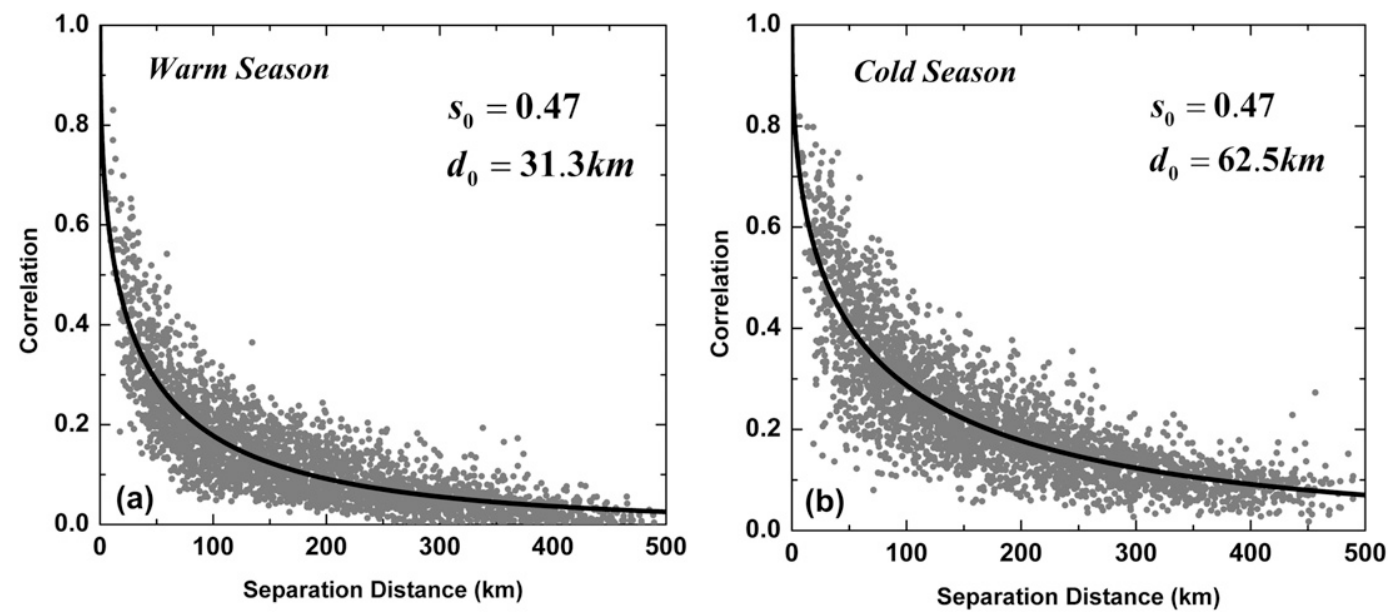

FIG. 9. Spatial correlation structure of hourly rainfall in the (left) warm season and (right) cold season. 

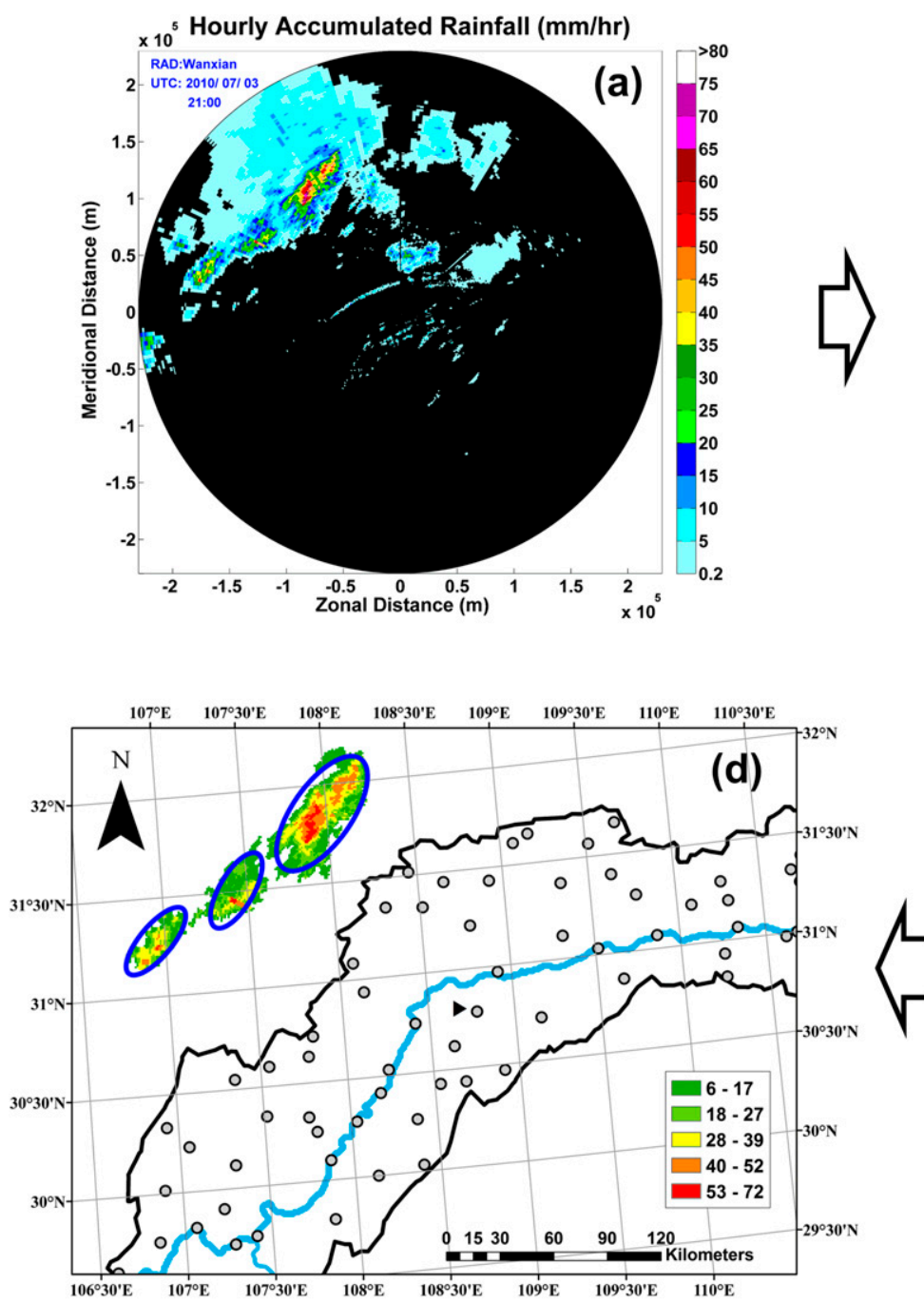
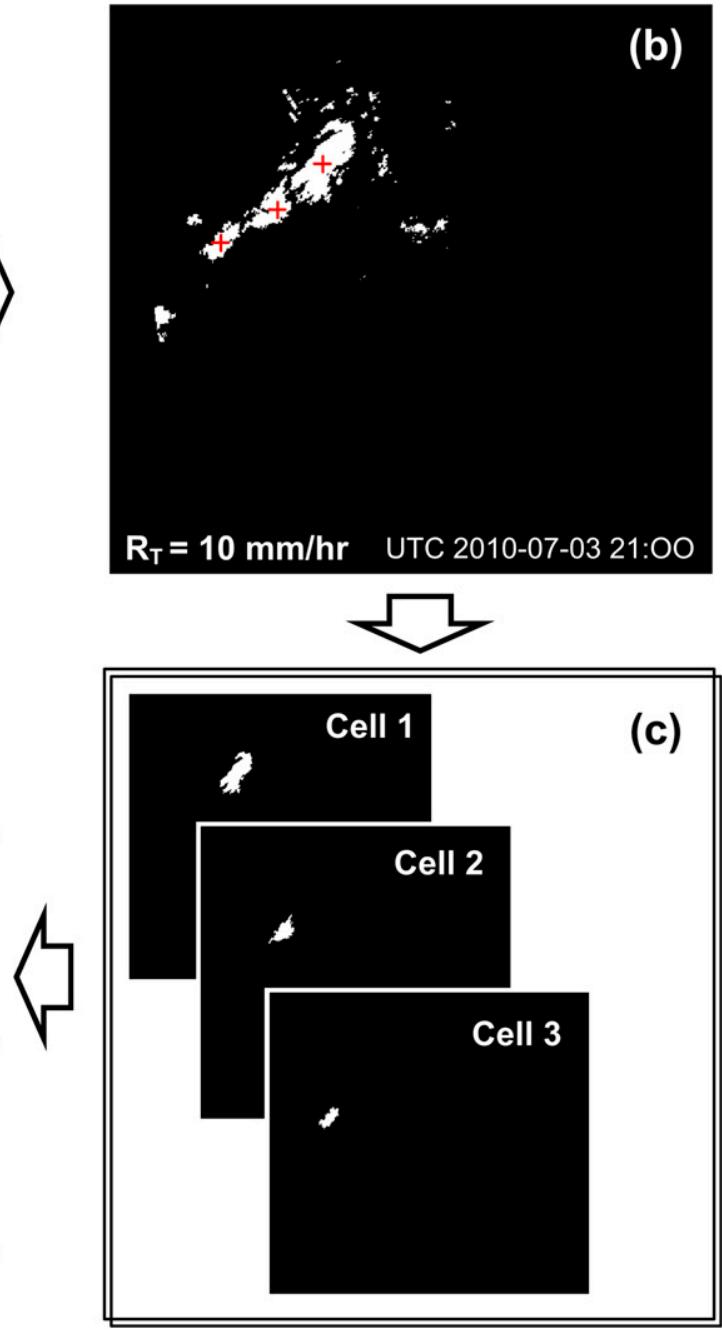

FIG. 10. Illustration of processing procedures to extract storm cells from radar QPE images.

radar QPE map (Fig. 10c) - an approach that is similar to the approach used in the Precipitation Estimation from Remotely Sensed Imagery Using Artificial Neural Networks-Cloud Classification System (PERSIANNCCS; Hong et al. 2007) but is much simpler, since the initial seeds are generated by manual screening in this study.

Step 3 is the storm-features analysis. As discussed in previous studies, the storm cells could be approximated by either a circular shape (Morin et al. 2006) or an elliptical shape (Dixon and Wiener 1993). Following the latter, which is a part of the Thunderstorm Identification, Tracking, Analysis, and Nowcasting (TITAN) system, we fit the shape of all the extracted storm cells by ellipses and estimate the shape parameters (Fig. 10d). The details of the ellipse approximation procedures may be found in appendix E of Dixon and Wiener (1993).

The rain-cell identification procedures are illustrated in Fig. 10. From Fig. 10a to Fig. 10d, rain cells are extracted from radar QPE images using threshold-based identification with region-growing algorithms. Then, all of the rain cells will be approximated by ellipses, which helps us to gain information about the shape features of local storms. Figure 11 shows an example of rain-cell identifications and ellipse approximations during a storm event on 4 July 2010.

All 17 rainstorm events collected during the 2010 summer and their spatial features are summarized in Table 2. In general, the life cycle of storm events in the TGR is short (6-8 h), except for the event on 3 July 2010 , which lasted $\sim 24 \mathrm{~h}$. Despite the short duration of TGR summer rainstorms, the total number of storm cells is 186 during 17 events, indicating that summer rainfall processes in the TGR always consist of several localized storm centers. A comparison of the statistics for different storm events in Table 2 shows great interevent variations of storms in TGR: the storm area ranges from 300 


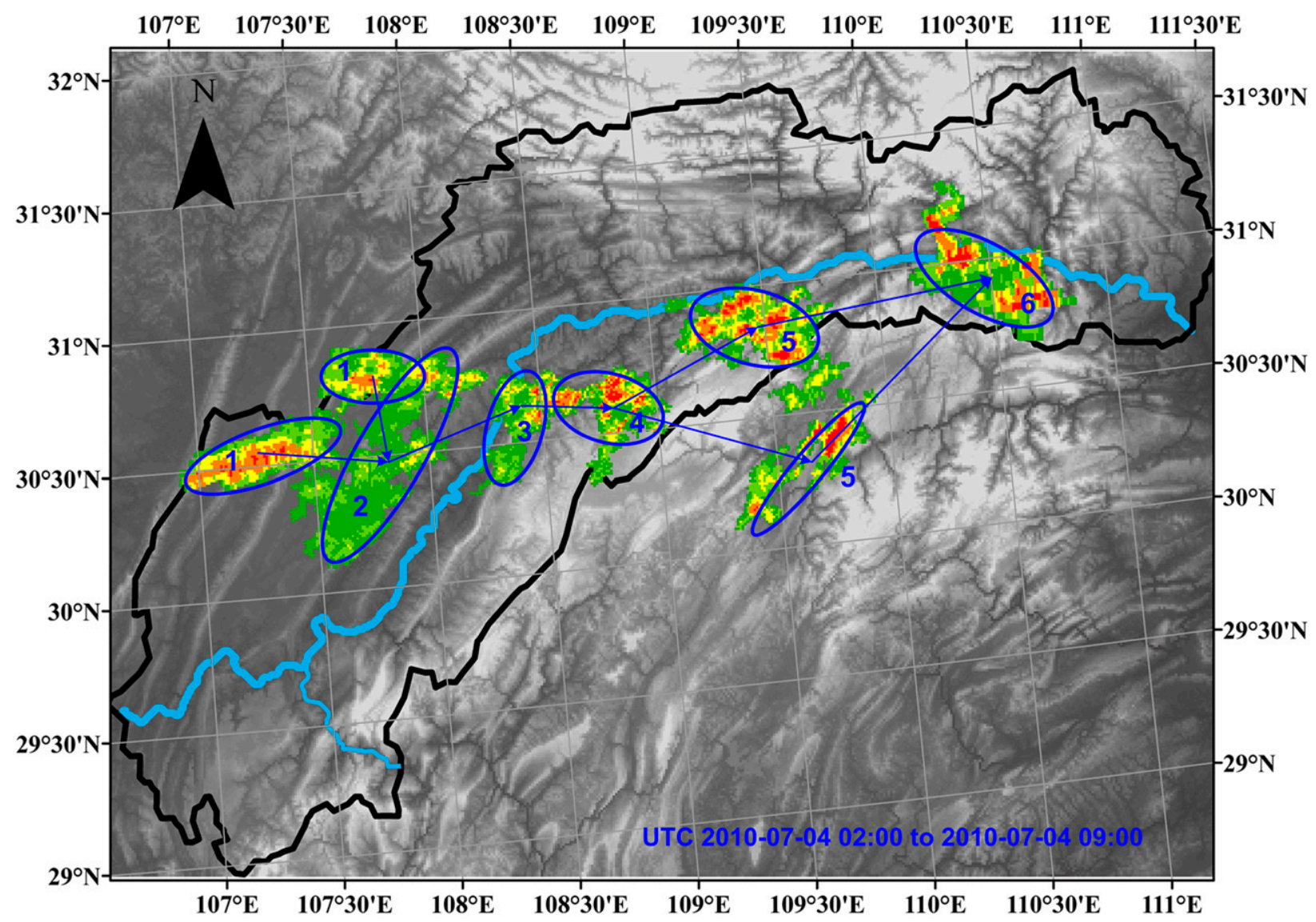

FIG. 11. Rain-cell identification and tracking for a 4 Jul 2010 event in the TGR (time labels 1-6 correspond to 0200, 0300,0400, 0500, 0700, and 0900 UTC, respectively).

to $1900 \mathrm{~km}^{2}$ and the major (minor) radii ( $R_{\text {major }}$ and $R_{\text {minor }}$, respectively, in the table) of estimated ellipses are within the range of $13-36 \mathrm{~km}(5-17 \mathrm{~km})$. On average the spatial scale in the minor direction is only one-half of that in the major direction, suggesting that highintensity rain cells in the TGR usually appear with a long and narrow shape. Given that the gauge density in the TGR is approximately one gauge per $770 \mathrm{~km}^{2}$ while summer rainfall decorrelates within $30 \mathrm{~km}$, this radarbased storm analysis indicates that the current gauge network in the TGR perhaps cannot capture the smallscale rainfall patterns adequately, especially for those localized high-intensity summer rainstorms.

Figure 12 represents the intra-event variations of rainstorm properties. For instance, during the long-lasting 3 July rainfall event, the coverage of storm cells roughly varies from 100 to $2800 \mathrm{~km}^{2}$ while the spatial extents in the minor and major directions are 5-22 and $10-50 \mathrm{~km}$, respectively. The variations of storm properties during three other events (8 July, 20 June, and 14 August) are also significant, as shown in Fig. 12. The intra-event variations, accompanying the interevent variations discussed above, to some extent demonstrate the difficulty in studying local rainstorms in the TGR.

Because the identification of storms also allowed calculation of the coordinates of rainstorms, we locate all of the storm centers (the location at which point it is identified as a rain cell) in Fig. 13. It is clear that most storms are located in the northern part of the TGR and that beyond the TGR the storms cluster around the west side of the Daba Mountains, in an area called Wanyuan, which is another well-known storm region along the Jialing River, one of the major tributaries of the Yangtze River. In comparing Fig. 13 (radar analysis) with Fig. 3 (gauge analysis), it is seen that the spatial pattern of rainstorm locations shows consistency with the maps of 6- and 12-h maximum rainfall to some degree, with both implying that most rainstorms are located in the northern part of the TGR.

\section{Summary and discussion}

In this study, utilizing gauge and newly available radar data, we have first investigated the spatiotemporal 
TABLE 2. Statistics of storm events during summer (June-August) 2010 in the TGR.

\begin{tabular}{|c|c|c|c|c|c|c|}
\hline No. & Date & Duration (h) & No. of storm cells & $R_{\text {minor }}(\mathrm{km})^{*}$ & $R_{\text {major }}(\mathrm{km})^{*}$ & Area $\left(\mathrm{km}^{2}\right)^{*}$ \\
\hline 1 & 7 Jun & 6 & 6 & 8.24 & 18.08 & 538 \\
\hline 2 & 20 Jun & 7 & 17 & 8.24 & 15.45 & 435 \\
\hline 3 & 23 Jun & 3 & 3 & 9.52 & 15.45 & 476 \\
\hline 4 & 24 Jun & 5 & 5 & 7.06 & 13.32 & 308 \\
\hline 5 & $3 \mathrm{Jul}$ & 26 & 43 & 12 & 24.25 & 1032 \\
\hline 6 & $4 \mathrm{Jul}$ & 6 & 6 & 11.82 & 22.22 & 856 \\
\hline 7 & $7 \mathrm{Jul}$ & 5 & 7 & 5.31 & 20.77 & 350 \\
\hline 8 & $8 \mathrm{Jul}$ & 7 & 10 & 15.37 & 35.63 & 1800 \\
\hline 9 & $15 \mathrm{Jul}$ & 7 & 12 & 10.97 & 18.62 & 691 \\
\hline 10 & $17 \mathrm{Jul}$ & 6 & 13 & 12.96 & 27.83 & 1176 \\
\hline 11 & $18 \mathrm{Jul}$ & 7 & 7 & 8.46 & 21.85 & 575 \\
\hline 12 & $30 \mathrm{Jul}$ & 8 & 12 & 7.64 & 13.45 & 337 \\
\hline 13 & $1 \mathrm{Aug}$ & 4 & 7 & 17.19 & 32.37 & 1897 \\
\hline 14 & 5 Aug & 6 & 13 & 12.39 & 24.4 & 1057 \\
\hline 15 & 14 Aug & 7 & 11 & 12.17 & 22.99 & 934 \\
\hline 16 & $20 \mathrm{Aug}$ & 5 & 5 & 17.31 & 32.79 & 1902 \\
\hline 17 & 21 Aug & 5 & 9 & 10 & 17.08 & 541 \\
\hline
\end{tabular}

* The numbers given are the mean value of all storm cells during the storm event.

variations of hourly rainfall in the mountainous Three Gorges region. We applied several analysis methods to characterize the general pattern of hourly rainfall, including spatial variations of summary statistics (mean, coefficient of variance, rainfall occurrence percentage, conditional mean rainfall, and maximum accumulated rainfall) and regionalization of the diurnal cycle. To characterize the spatial dependence, we also estimated the spatial correlation scale on the basis of gauge observations. Further, geometrical features of summer rainstorms were analyzed by high-resolution radar rainfall data. The multisensor investigation reveals many interesting spatiotemporal features of rainfall in the TGR, as well as the deficiency of the current gauge network, and we summarize the major findings as follow:

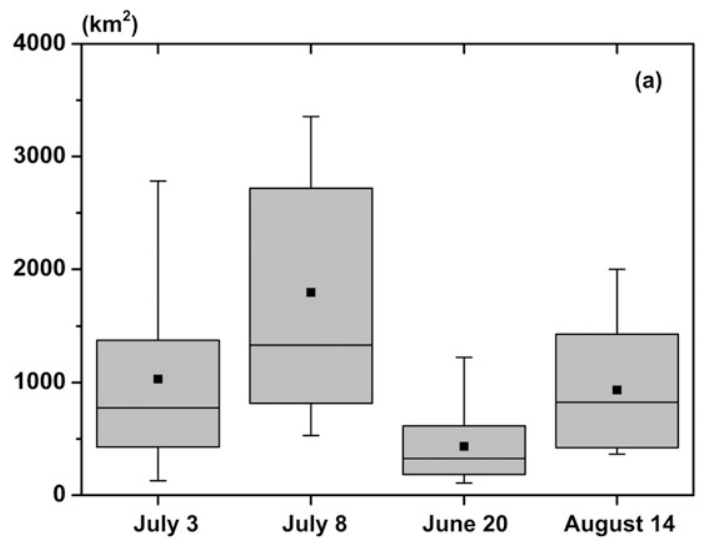

1) Hourly rainfall in the TGR exhibits a right-tailed distribution with relatively high temporal variability, and spatially the orographic effects will locally intensify rainfall in the form of more events and larger amounts.

2) The monsoon climate interacts with local terrain to shape complex rainfall regimes in the TGR: large rainfall amounts (exceeding $1000 \mathrm{~mm}$ ) are observed in both northern and southern mountainous regions, but in contrast, high-intensity rainfall mainly occurs in the northern TGR. For the western TGR near Chongqing, the total rainfall amount is limited, although light rainfall occurs frequently.

3) The maximum accumulated rainfall at subdaily scales $(1-12 \mathrm{~h})$ tends to occur in most areas of the

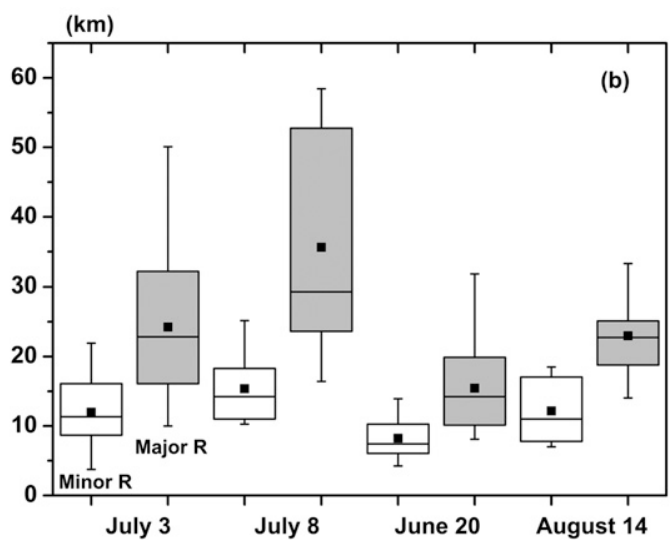

FIG. 12. Boxplots of estimated rainstorm features [(left) storm areas and (right) storm radii] during four typical storm events. The squares represent the mean value. Each box ranges from the lower 25 th quartile to the upper 75 th quartile. The median is presented by the line inside the box. The whiskers extend out to the largest and smallest values. 


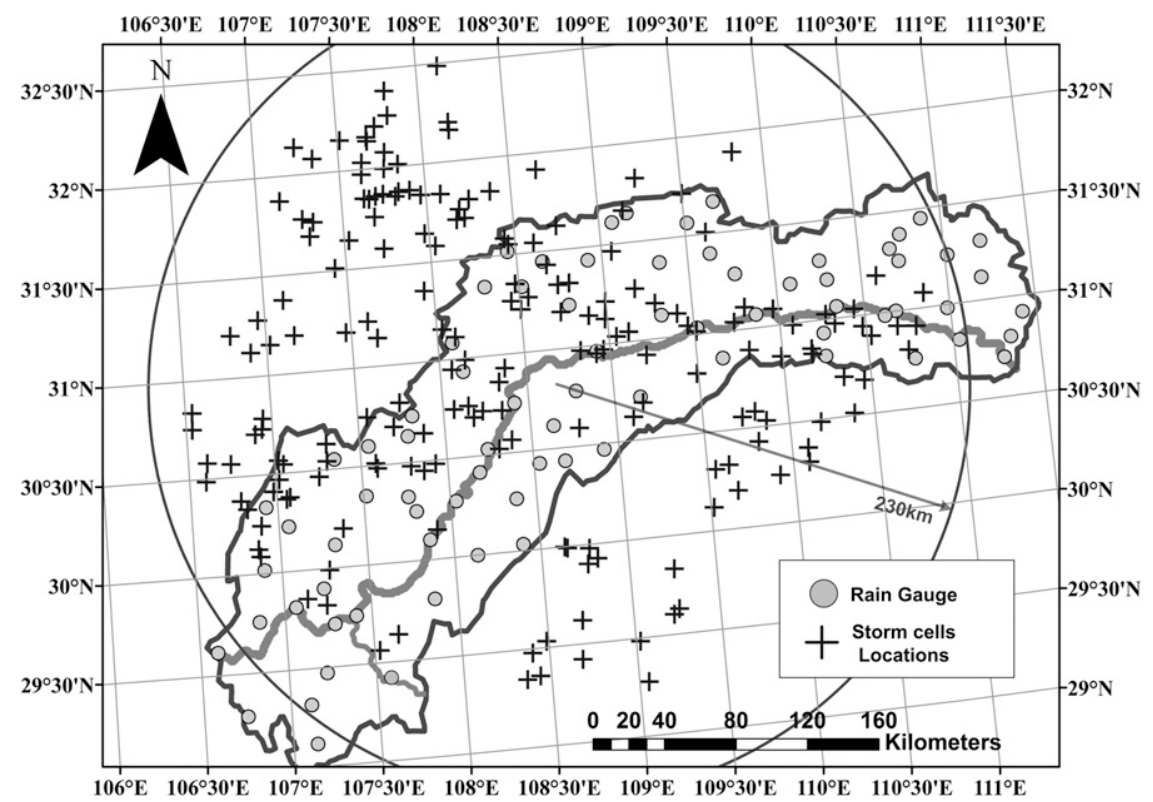

FIG. 13. Storm-cell locations identified by radar rainfall products during summer 2010. The plus signs indicate the estimated centers of summer storm cells.

TGR, but 24-h maximum rainfall always shows its greatest value in northern TGR near the Daba Mountain.

4) The diurnal cycle shifts from a morning peak $(\sim 0800$ Beijing time) in the western TGR to a late-afternoon $(\sim 1800)$ maximum mode in the eastern TGR, and in the intermediate transition zone a mixed pattern with two peaks emerges.

5) The empirical model shows that the "correlation scale" $d_{0}$ of hourly rainfall is about $40 \mathrm{~km}$ in the TGR. Further, the spatial correlation structure is dependent on the temporal averaging scale as well as the season, with the correlation scale increasing from $30 \mathrm{~km}$ in summer to $60 \mathrm{~km}$ in winter.

6) Summer storms in TGR are characterized by short durations $(6-8 \mathrm{~h})$ and highly localized patterns (517 and $13-36 \mathrm{~km}$ in the minor and major radius directions, respectively) as based on newly available radar data, suggesting that the current gauge network is perhaps insufficient to capture localized rainstorms.

The results presented herein provide both qualitative and quantitative information to understand the spatiotemporal variations of rainfall regimes in the TGR from the mesoscale to the small scale, and knowledge gained by this study can further benefit regional hydrological and meteorological applications.

With only two years of gauge data and only one summer of radar data, however, there is one major concern about the potential impacts of the interannual variability of rainfall on the results presented in this paper. A previous study over the TGR (Xiao et al. 2010) actually shows that limited temporal coverage of the dataset will neglect the decadal variations of rainfall and thus lead to unreasonable assessment. Keeping this in mind, a yearby-year reanalysis is also implemented, using the analysis methods mentioned above but with data from the first year (2009-10) and the second year (2010-11), respectively. The results indicate that the major conclusions hold during each year and that the general space-time pattern is consistent. It is noteworthy that the diurnal cycle of region III shows an obvious year-byyear change, however, suggesting that the subdaily rainfall regimes could be partly complicated by the interannual variations of monsoon activities. Thus, the analysis methods presented here should be applied to future investigations when long-term high-resolution data become available.

Given the deficiencies associated with each rainfall measurement, this study also suggests additional information that can be provided by synthesizing multiple data sources, which is demonstrated to be more effective and complete than use of each individual observational system in characterizing the precipitation pattern. In the future, we need to take into consideration static terrain factors, as well as the dynamic information from other measurements of the atmospheric environment, such as the wind direction, lightning, and radar QPE, to optimally estimate rainfall in mountainous areas. Therefore, 
synthesizing multiple data sources to analyze the spacetime structure of rainfall and generate multisensor precipitation estimates, as proposed in this paper and in many other studies (Gupta et al. 2006; Shrestha et al. 2011; Zhang et al. 2012), should be recommended for future in-depth investigations, since it is a more informative way to explore the multifaceted nature of rainfall variations.

Acknowledgments. This research was supported by the National Natural Science Funds for Distinguished Young Scholar project (Project 51025931) and the joint research project (sklhse-2010-A-03) funded by the State Key Laboratory of Hydroscience and Engineering and the State Key Laboratory of Severe Weather in China. The first author was also partially supported by the Tsinghua Scholarship for Overseas Graduate Studies. The first author thanks the Hydrometeorology and Remote Sensing Laboratory (HyDROS Lab; http://hydro. ou.edu) at the National Weather Center in Norman, Oklahoma, for its support during his visits and acknowledges Manabendra Saharia for his language editing, which has greatly improved this paper. The authors thank the three anonymous reviewers for their insightful comments.

\section{REFERENCES}

Balme, M., T. Vischel, T. Lebel, C. Peugeot, and S. Galle, 2006: Assessing the water balance in the Sahel: Impact of small scale rainfall variability on runoff: Part 1: Rainfall variability analysis. J. Hydrol., 331, 336-348, doi:10.1016/ j.jhydrol.2006.05.020.

Berne, A., and W. F. Krajewski, 2013: Radar for hydrology: Unfulfilled promise or unrecognized potential? Adv. Water Resour., 51, 357-366, doi:10.1016/j.advwatres.2012.05.005.

Buytaert, W., R. Celleri, P. Willems, B. D. Bièvre, and G. Wyseure, 2006: Spatial and temporal rainfall variability in mountainous areas: A case study from the south Ecuadorian Andes. J. Hydrol., 329, 413-421, doi:10.1016/j.jhydrol.2006.02.031.

Carbone, R. E., J. D. Tuttle, D. A. Ahijevych, and S. B. Trier, 2002: Inferences of predictability associated with warm season precipitation episodes. J. Atmos. Sci., 59, 2033-2056, doi:10.1175/1520-0469(2002)059<2033:IOPAWW>2.0.CO;2.

Changjiang Water Resources Commission, 1997: Hydrology Research for Three Gorges Project (in Chinese). Hubei Science and Technology Press, 313 pp.

Ciach, G. J., and W. F. Krajewski, 2006: Analysis and modeling of spatial correlation structure in small-scale rainfall in central Oklahoma. Adv. Water Resour., 29, 1450-1463, doi:10.1016/ j.advwatres.2005.11.003.

Clark, M. P., and A. G. Slater, 2006: Probabilistic quantitative precipitation estimation in complex terrain. J. Hydrometeor., 7, 3-22, doi:10.1175/JHM474.1.

Daly, C., R. P. Neilson, and D. L. Phillips, 1994: A statisticaltopographic model for mapping climatological precipitation over mountainous terrain. J. Appl. Meteor., 33, 140-158, doi:10.1175/1520-0450(1994)033<0140:ASTMFM>2.0.CO;2.
Delrieu, G., B. Boudevillain, J. Nicol, B. Chapon, P. E. Kirstetter, H. Andrieu, and D. Faure, 2009: Bollène-2002 Experiment: Radar quantitative precipitation estimation in the CévennesVivarais region, France. J. Appl. Meteor. Climatol., 48, 14221447, doi:10.1175/2008JAMC1987.1.

Dixon, M., and G. Wiener, 1993: TITAN: Thunderstorm Identification, Tracking, Analysis, and Nowcasting-A radar-based methodology. J. Atmos. Oceanic Technol., 10, 785-797, doi:10.1175/1520-0426(1993)010<0785:TTITAA > 2.0.CO;2.

Ebert, E. E., J. E. Janowiak, and C. Kidd, 2007: Comparison of near-real-time precipitation estimates from satellite observations and numerical models. Bull. Amer. Meteor. Soc., 88, 4764, doi:10.1175/BAMS-88-1-47.

Foufoula-Georgiou, E., and V. Vuruputur, 2001: Patterns and organization in precipitation. Spatial Patterns in Catchment Hydrology: Observations and Modelling, R. Grayson and G. Blöschl, Eds., Cambridge University Press, 82-104.

Germann, U., G. Galli, M. Boscacci, and M. Bolliger, 2006: Radar precipitation measurement in a mountainous region. Quart. J. Roy. Meteor. Soc., 132, 1669-1692, doi:10.1256/qj.05.190.

Gourley, J. J., D. P. Jorgensen, S. Y. Matrosov, and Z. L. Flamig, 2009: Evaluation of incremental improvements to quantitative precipitation estimates in complex terrain. J. Hydrometeor., 10, 1507-1520, doi:10.1175/2009JHM1125.1.

Gupta, R., V. Venugopal, and E. Foufoula-Georgiou, 2006: A methodology for merging multisensor precipitation estimates based on expectation-maximization and scale-recursive estimation. J. Geophys. Res., 111, D02102, doi:10.1029/ 2004JD005568.

Haile, A. T., T. Rientjes, A. Gieske, and M. Gebremichael, 2009: Rainfall variability over mountainous and adjacent lake areas: The case of Lake Tana basin at the source of the Blue Nile River. J. Appl. Meteor. Climatol., 48, 1696-1717, doi:10.1175/ 2009JAMC2092.1.

Harris, D., E. Foufoula-Georgiou, K. Droegemeier, and T. Levit, 2001: Multiscale statistical properties of a high-resolution precipitation forecast. J. Hydrometeor., 2, 406-418, doi:10.1175/ 1525-7541(2001)002<0406:MSPOAH > 2.0.CO;2.

Heistermann, M., and D. Kneis, 2011: Benchmarking quantitative precipitation estimation by conceptual rainfall-runoff modeling. Water Resour. Res., 47, W06514, doi:10.1029/2010WR009153.

Hong, Y., R. Adler, and G. Huffman, 2006: Evaluation of the potential of NASA multi-satellite precipitation analysis in global landslide hazard assessment. Geophys. Res. Lett., 33, L22402, doi:10.1029/2006GL028010.

— D. Gochis, J. Cheng, K. Hsu, and S. Sorooshian, 2007: Evaluation of PERSIANN-CCS rainfall measurement using the NAME event rain gauge network. J. Hydrometeor., 8, 469482, doi:10.1175/JHM574.1.

Kucera, P. A., W. F. Krajewski, and C. B. Young, 2004: Radar beam occultation studies using GIS and DEM technology: An example study of Guam. J. Atmos. Oceanic Technol., 21, 995-1006, doi:10.1175/1520-0426(2004)021<0995:RBOSUG > 2.0.CO;2.

Li, M., D. Yang, J. Chen, and S. S. Hubbard, 2012: Calibration of a distributed flood forecasting model with input uncertainty using a Bayesian framework. Water Resour. Res., 48, W08510, doi:10.1029/2010WR010062.

Li, Z., D. Yang, and F. Tian, 2013: Flood forecast of the Yangtze Three Gorges region based on ground-observed rainfall (in Chinese). J. Hydrol. Eng., 32, 44-49.

Miller, N. L., J. M. Jin, and C.-F. Tsang, 2005: Local climate sensitivity of the Three Gorges Dam. Geophys. Res. Lett., 32, L16704, doi:10.1029/2005GL022821. 
Mishra, A. K., and P. Coulibaly, 2009: Developments in hydrometric network design: A review. Rev. Geophys., 47, RG2001, doi:10.1029/2007RG000243.

Morin, E., D. C. Goodrich, R. A. Maddox, X. Gao, H. V. Gupta, and S. Sorooshian, 2006: Spatial patterns in thunderstorm rainfall events and their coupling with watershed hydrological response. Adv. Water Resour., 29, 843-860, doi:10.1016/ j.advwatres.2005.07.014.

Nicótina, L., E. Alessi Celegon, A. Rinaldo, and M. Marani, 2008: On the impact of rainfall patterns on the hydrologic response. Water Resour. Res., 44, W12401, doi:10.1029/2007WR006654.

Papalexiou, S. M., and D. Koutsoyiannis, 2012: Entropy based derivation of probability distributions: A case study to daily rainfall. Adv. Water Resour., 45, 51-57, doi:10.1016/ j.advwatres.2011.11.007.

Qi, Y., J. Zhang, and P. Zhang, 2013: A real-time automated convective and stratiform precipitation segregation algorithm in native radar coordinates. Quart. J. Roy. Meteor. Soc., 139B, 2233-2240, doi:10.1002/qj.2095.

Rodríguez-Iturbe, I., B. F. dePower, and J. B. Valdés, 1987: Rectangular pulses point process models for rainfall: Analysis of empirical data. J. Geophys. Res., 92, 9645-9656, doi:10.1029/ JD092iD08p09645.

Shrestha, R., P. R. Houser, and V. G. Anantharaj, 2011: An optimal merging technique for high-resolution precipitation products. J. Adv. Model. Earth Syst., 3, M12003, doi:10.1029/2011MS000062.

Smith, J. A., and W. F. Krajewski, 1991: Estimation of the mean field bias of radar rainfall estimates. J. Appl. Meteor., 30, 397-412, doi:10.1175/1520-0450(1991)030<0397:EOTMFB >2.0.CO;2.

Sorooshian, S., and Coauthors, 2011: Advanced concepts on remote sensing of precipitation at multiple scales. Bull. Amer. Meteor. Soc., 92, 1353-1357, doi:10.1175/2011BAMS3158.1.

Wang, C. C., G. T. J. Chen, and R. E. Carbone, 2004: A climatology of warm-season cloud patterns over East Asia based on GMS infrared brightness temperature observations. Mon. Wea. Rev., 132, 1606-1629, doi:10.1175/1520-0493(2004)132<1606: ACOWCP $>2.0 . C O ; 2$.

Winchell, M., H. V. Gupta, and S. Sorooshian, 1998: On the simulation of infiltration- and saturation-excess runoff using radar-based rainfall estimates: Effects of algorithm uncertainty and pixel aggregation. Water Resour. Res., 34, 2655-2670, doi:10.1029/98WR02009.
Wu, H., R. F. Adler, Y. Hong, Y. Tian, and F. Policelli, 2012: Evaluation of global flood detection using satellite-based rainfall and a hydrologic model. J. Hydrometeor., 13, 1268 1284, doi:10.1175/JHM-D-11-087.1.

Wu, L., Q. Zhang, and Z. Jiang, 2006: Three Gorges Dam affects regional precipitation. Geophys. Res. Lett., 33, L13806, doi:10.1029/2006GL026780.

Xiao, C., R. Yu, and Y. Fu, 2010: Precipitation characteristics in the Three Gorges Dam vicinity. Int. J. Climatol., 30, 2021-2024, doi:10.1002/joc.1963.

Young, C. B., B. R. Nelson, A. A. Bradley, J. A. Smith, C. D. Peters-Lidard, A. Kruger, and M. L. Baeck, 1999: An evaluation of NEXRAD precipitation estimates in complex terrain. J. Geophys. Res., 104, 19691-19703, doi:10.1029/1999JD900123.

Yu, R., T. Zhou, A. Xiong, Y. Zhu, and J. Li, 2007: Diurnal variations of summer precipitation over contiguous China. Geophys. Res. Lett., 34, L01704, doi:10.1029/2006GL028129.

Zhang, J., and Coauthors, 2011: National Mosaic and Multi-Sensor QPE (NMQ) System: Description, results, and future plans. Bull. Amer. Meteor. Soc., 92, 1321-1338, doi:10.1175/ 2011BAMS-D-11-00047.1.

-, Y. Qi, D. Kingsmill, and K. Howard, 2012: Radar-based quantitative precipitation estimation for the cool season in complex terrain: Case studies from the NOAA Hydrometeorology Testbed. J. Hydrometeor., 13, 1836-1854, doi:10.1175/ JHM-D-11-0145.1.

Zhang, Y., S. Zhang, and Z. Wang, 1999: Analysis on the storm and flood at Yangtze Three Gorges region (in Chinese). Yangtze River, 30, 12-13.

Zhao, F., and M. Shepherd, 2012: Precipitation changes near Three Gorges Dam, China. Part I: A spatiotemporal validation analysis. J. Hydrometeor., 13, 735-745, doi:10.1175/ JHM-D-11-061.1.

- H. Deng, and X. Zhao, 2010: Rainfall regime in Three Gorges area in China and the control factors. Int. J. Climatol., 30, 1396-1406, doi:10.1002/joc.1978.

Zhou, M., F. Tian, U. Lall, and H. Hu, 2011: Insights from a joint analysis of Indian and Chinese monsoon rainfall data. Hydrol. Earth Syst. Sci., 15, 2709-2715, doi:10.5194/hess-15-2709-2011.

Zhuo, H., P. Zhao, and T. Zhou, 2014: Diurnal cycle of summer rainfall in Shandong of eastern China. Int. J. Climatol., 34, 742-750, doi:10.1002/joc.3718. 